\title{
Wear and Friction Property of Laser Sintered Graphene Nickel Composite Coating
}

Zengrong $\mathrm{Hu}^{1,2, \mathrm{a}}$, Zhuqiang Shao ${ }^{1, \mathrm{~b}}$, Feng $\mathrm{Chen}^{2, \mathrm{c}}$,Jiale $\mathrm{Xu}^{3, \mathrm{~d}}$, Changjun Chen $^{4, e_{*}}$

${ }^{1}$ School of Urban Rail Transportation, Soochow University, Suzhou, Jiangsu, 215131, China

${ }^{2}$ College of Mechanical and Electrical Engineering, Nanjing University of Aeronautics and Astronautics, Nanjing, Jiangsu, 210016,China

${ }^{3}$ School of Mechanical Engineering, Jiangsu University, Jiangsu, 212013, China

${ }^{4}$ School of Mechanical and Electrical Engineering, Soochow University, Suzhou, Jiangsu, 215131, China

aemail: zengronghu@126.com, bemail: 654051802@qq.com,

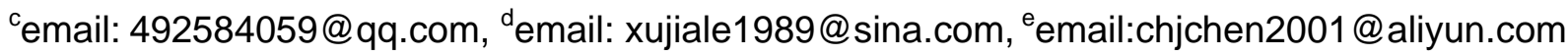

Keywords: Graphene, Composite coating, Nickel, Laser sintering

\begin{abstract}
Graphene sheets and nickel powder were dispersed into Polyvinyl Alcohol (PVA) solution by magnetic stirring, and then pre-coating the mixed solution on the polished AISI4140 substrate. And after laser sintering, graphene nickel composite coating was successfully fabricated. Microstructures and composition of the composite coating before and after wear and friction experiments was studied by using Scanning Electron Microscopy (SEM) and Transmission Electron Microscopy (TEM), Energy Dispersive Spectrometer (EDS) and Raman spectroscopy. Raman spectrum, SEM and TEM results proved that graphene sheets were dispersed in the composite coating. Nano indentation test results showed that graphene nickel composite coating had been greatly strengthened, and for pure nickel coating, the average friction coefficient was 0.35 , while for the $10 \%$ graphene nickel coating, it was reduced to 0.13 .
\end{abstract}

\section{Introduction}

Nickel has many exceptional properties, such as, high toughness, high-temperature performance, corrosion resistance and high strength. Thus nickel based composite coatings have been wildly studied and applied in many industry fields. The most favorite strengthening materials for nickel base composite coatings are those hard particles, such as $\mathrm{WC}[1,2], \mathrm{Al}_{2} \mathrm{O}_{3}[3,4], \mathrm{SiC}[5,6]$, TiN[7, 8]. In order to improve the wear resistance performance of nickel based composite coatings, it is necessary to find new and better reinforcements. It was proved that carbon materials, such as, graphite powder[9, 10], CNTs[11, 12] and especially graphene[13-15], are excellent strengthening materials for many composites and composite coatings.

Graphene (Gr) is a new material, which has only one carbon atom layer forming flat honeycomb like lattice. It has many exceptional properties, such as, excellent electric and thermal property[16, 17], high Young's modulus and tensile stress[18, 19] and outstanding wear resistance properties. So it was reasonable to combining the advantages of graphene and nickel to make the efforts to fabricate graphene nickel composite coatings. It has been reported that graphene was an effective reinforcement for nickel[14, 20]. Graphene dispersion is still a common problem, however, for wear resistance coating, it is not a critical problem.

Here, graphene nickel composite coating was fabricated by laser sintering technique. Laser sintering is a rapid heating and cooling process, which should help graphene sheets survival in the composite coating. 


\section{Experiments}

Materials: The AISI 4140 steel plate were used as substrate. The nickel powders (average diameter less than $1 \mu \mathrm{m}$, Sigma-Aldrich Co.) and multi-layer $\mathrm{COOH}$ rich graphene sheets (average $\mathrm{X} \& \mathrm{Y}$ dimension less than $2 \mu \mathrm{m}$, Cheap Tubes, Inc.) were used in this experiment.

Laser sintering experiments: Nickel powder, graphene sheets and PVA were used to make two kinds of solution by magnetic stirring. And coating the AISI 4140 substrate with the previous made solutions by using a dropper. An IPG fiber laser system was used to perform the laser sintering process at the frequency of $50 \mathrm{kHz}$. The samples were put into a transparent chamber which filled with $\mathrm{N}_{2}$ gas. The detailed information can be obtained from our previous works[14].

Microstructure characterization: A Hitachi S-4800 Field emission SEM was used to study the surface morphology and microstructures. The Raman spectra were obtained by a HORIBA LabRAM HR800 Raman spectrometer (HORIBA Jobin Yvon, NJ, USA). A FEI Nova 200 focused ion beam (FIB) system was used to prepare TEM samples by lift-out method. The microstructure images were obtained by the FEI Titan system operating at $300 \mathrm{keV}$.

\section{Results and discussion}

\section{Microstructure of graphene nickel composite coating}

Fig.1a shows the surface image of the composite coating after laser sintering. It can be seen that the laser sintering tracks appeared on the sample surface and the surface was smooth. Fig.1b is SEM image shows the surface morphology of the composite coating. The graphene sheets shape can be observed on the image. It perhaps due to the graphene sheets connected each other during nickel powder melting and solidification process.

Fig.1c and d are TEM images of the graphene nickel composite coating. It can be seen from Fig.1c that graphene sheet were dispersed in the nickel matrix homogenously. Fig.1d shows graphene embedded in the nickel matrix. The insert image is the select area electron diffraction (SAED) pattern. It is the typical SAED pattern of graphene. The other areas are nickel. This proved that after laser sintering graphene sheets were survived in the coating layer.
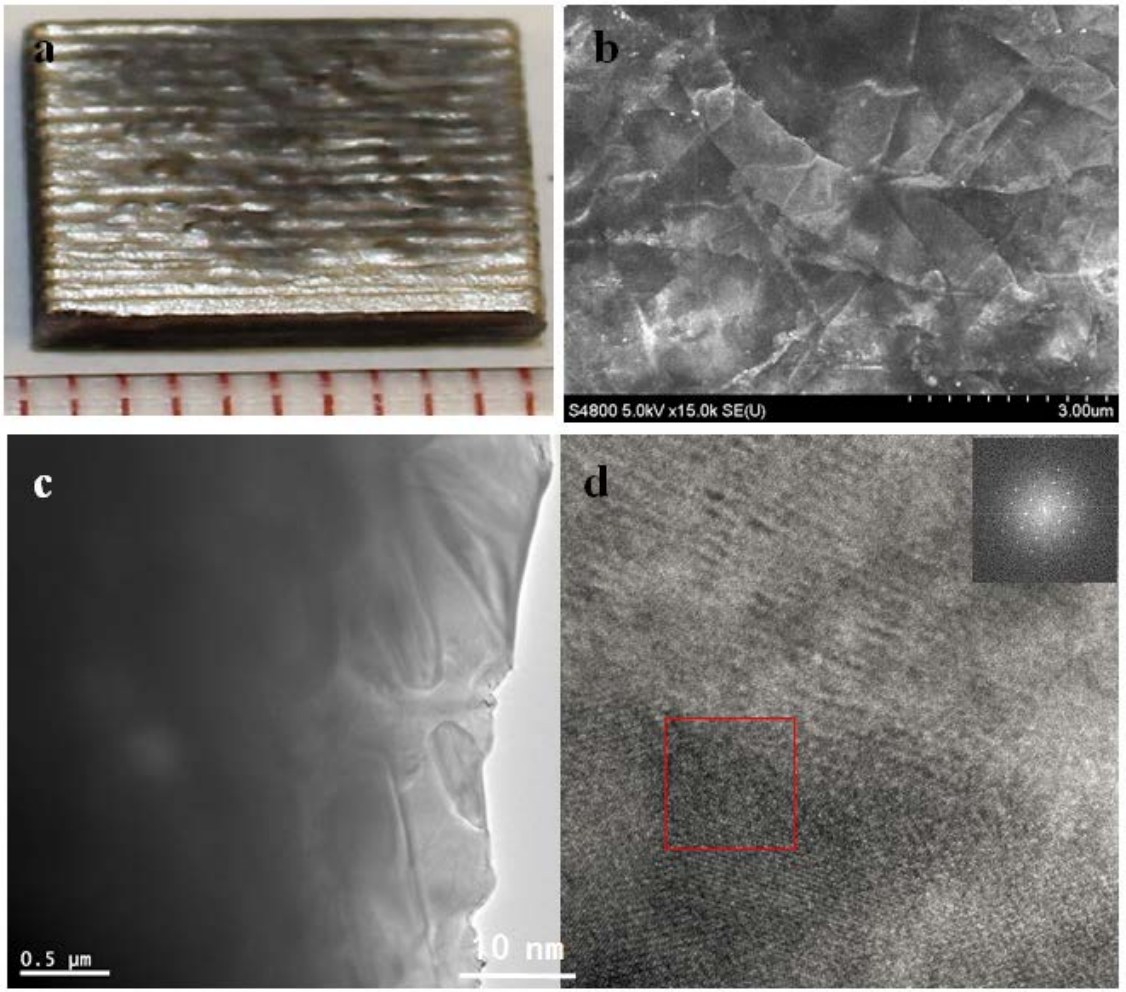

Fig.1. Laser sintered graphene nickel composite coating, (a) sample image, (b) surface morphology,

(c) TEM image and (d) TEM image with inserted graphene SAED pattern. 


\section{Raman spectrum analysis}

Raman spectroscopy was employed to characterize laser sintered graphene nickel composite coatings. Fig. 2 shows the Raman spectra of laser sintered graphene nickel composite coatings. It shows the outstanding peaks at $\sim 1329.9$, $\sim 1577.8$ and $\sim 2677.6 \mathrm{~cm}^{-1}$, corresponding to the multilayer grapnene's D peak, G peak and 2D peak, respectively[21-24]. It was also proved that graphene sheets were survived in the laser sintering process; graphene nickel composite coatings were successfully fabricated.

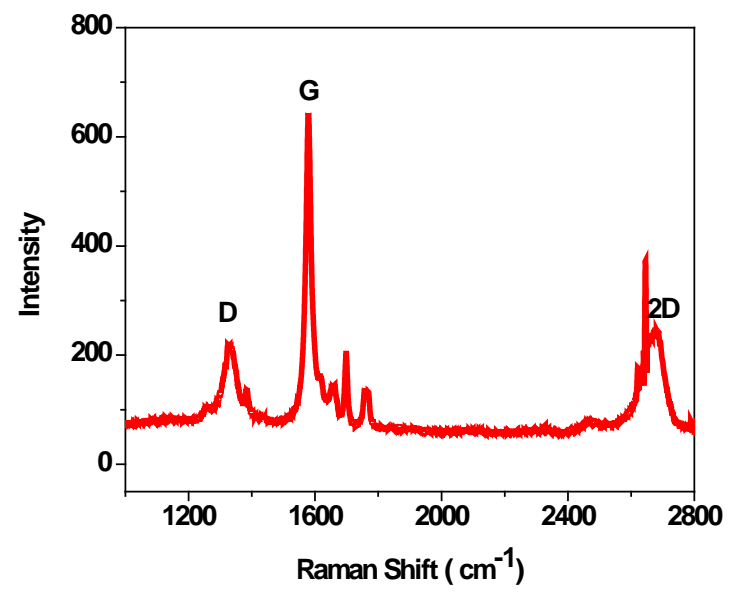

Fig.2 Raman spectrum of graphene nickel coating layer.

\section{Nano mechanical properties of laser sintered graphene nickel composite coatings}

Nanoindentation technique, which was used wildly for the study of mechanical properties of materials at nanoscale[25], was employed to characterize the properties of the graphene nickel composite coatings. A Hysitron Tribo indenter was used with the method descried by Oliver and Pharr[26], and a Berkovich tip was used for the nanoindentation test. Fig.3a show the hardness-contact depth curves of graphene nickel composite coatings and pure nickel coatings. It was measured on sample surface with increasing load. It can be seen that graphene nickel composite coating has much higher hardness than laser sintered pure nickel coatings. The average hardness value of graphene nickel composite coatings is about $12 \mathrm{GPa}$, while for pure nickel coatings, the average hardness value is about $7 \mathrm{GPa}$.

Fig.3b shows the modulus-contact depth curves of graphene nickel composite coatings and laser sintered pure nickel coatings. It has the same tendency as hardness curves. The average modulus value of graphene nickel composite coatings is $193.04 \mathrm{GPa}$, while the average modulus value of laser sintered pure nickel coatings is $159 \mathrm{GPa}$. It has a $21.4 \%$ increase. This illustrated that the composite coatings were obviously strengthened.
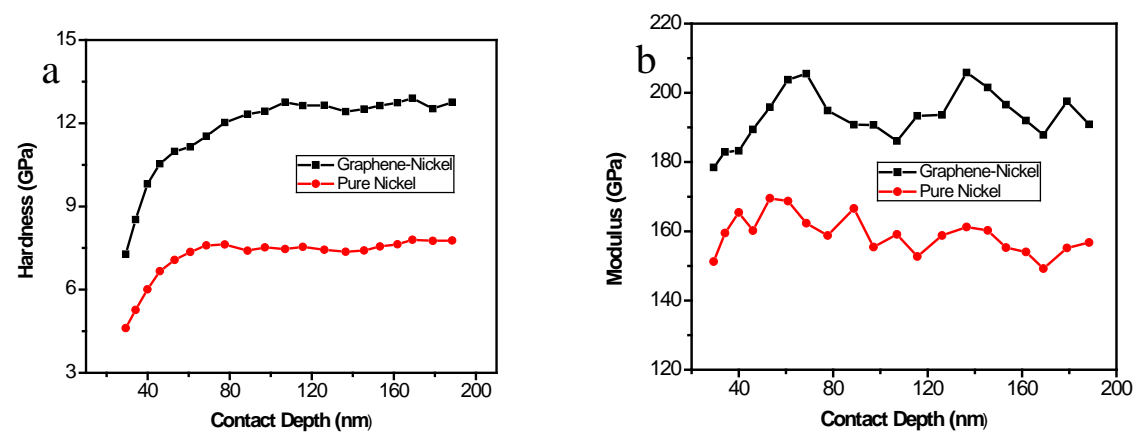

Fig. 3 Nanoindentation test results of laser sintered graphene nickel composite coatings, (a) hardness, (b) modulus.

\section{Wear and frication property}

Fig. 4 shows the low magnification SEM images of the worn surface of different graphene content graphene nickel composite coatings and pure nickel coatings. It can be clearly seen from those images, that with the graphene content increasing, the worn surface become smoother and the 
amount of the wear lost is decreased. Although the magnifications of these images are slightly different, it is still can be found that the width of the wear tracks were decreased as the graphene content increasing. Plastic deformation can be observed on all the worn surface of $\mathrm{Ni}$ and $\mathrm{Gr}-\mathrm{Ni}$ composite. However, as graphene content increasing, abrasive dusts were decreasing and plastic deformation and adhesive wear and abrasive wear were weakened. It was due to the hardness of composites were improved and also graphene sheets acted as load bearing and solid lubrication components in the coating layer. Graphene Nano sheets behaved as a solid lubricant and reduced the plastic deformation by smearing on the worn materials substrate[15, 27]. Thus, it made the composites worn out less.
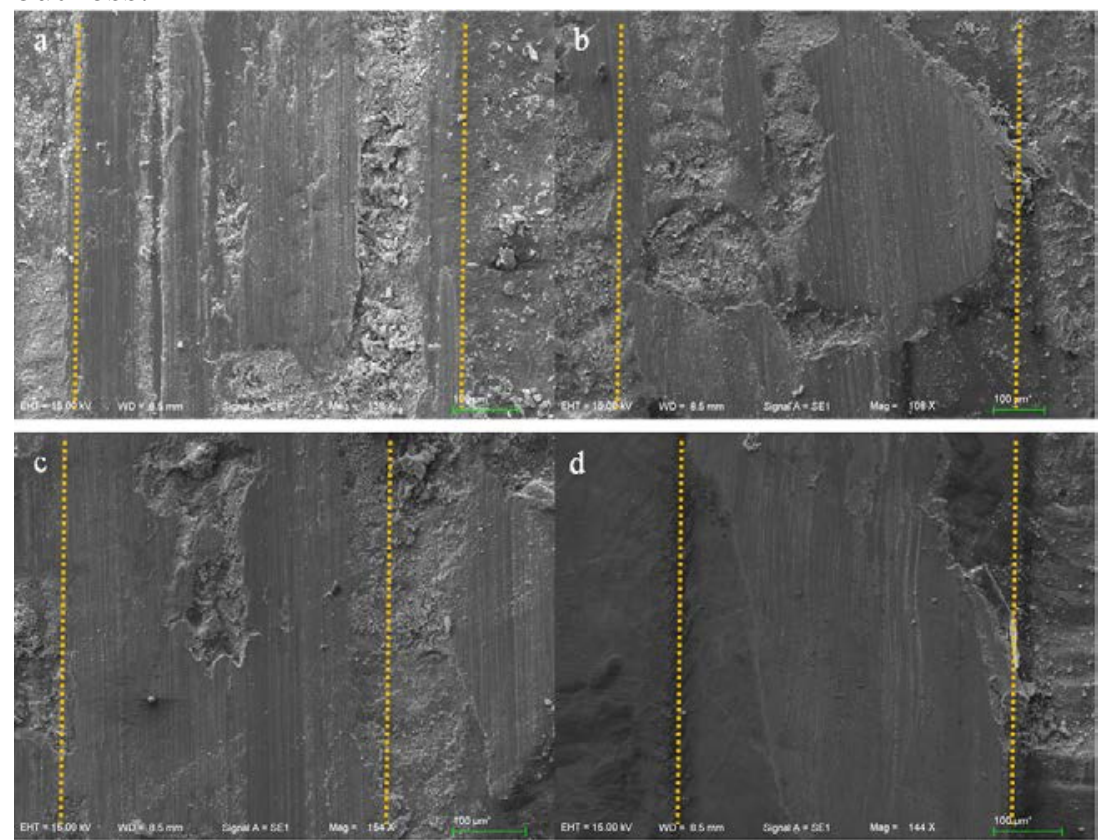

Fig. 4 Low magnification SEM morphologies of the wear tracks of graphene nickel composite coatings with different graphene content; (a) Ni, (b)1\% Gr, (c) $5 \% \mathrm{Gr}$ and (d) $10 \% \mathrm{Gr}$ at a constant sliding speed of $25 \mathrm{~mm} / \mathrm{s}$ for $5 \mathrm{~min}$.

Fig. 5 shows high magnification SEM images of worn surfaces of laser sintered pure nickel coatings and graphene nickel composite coatings. For the low graphene content samples, the surfaces showed plastic deformation and which were decreasing with the graphene content increasing. This was due to load bearing and lubricating effect of the graphene Nano sheets, which were dispersed in the nickel matrix. Experimental observations revealed that all worn surfaces have obvious furrow grooves, which should be made by hard particles. These hard particles maybe oxide or carbide. As shown in Fig. 6 EDS spectra of laser sintered pure nickel coatings illustrated high carbon and oxygen content in the selected particle. The carbon maybe come from laser sintered PVA or the substrate, and the oxygen maybe come from air during wear and frication experiments.

During the experiments, for the low graphene content composite coatings, there were more matrix materials contacted with the ball tip. This caused more severe wear on the contacting points. When the graphene content increasing the composite coatings were improved in both strength and the lubrication condition, and the real metal-metal contact area was also decreased. 

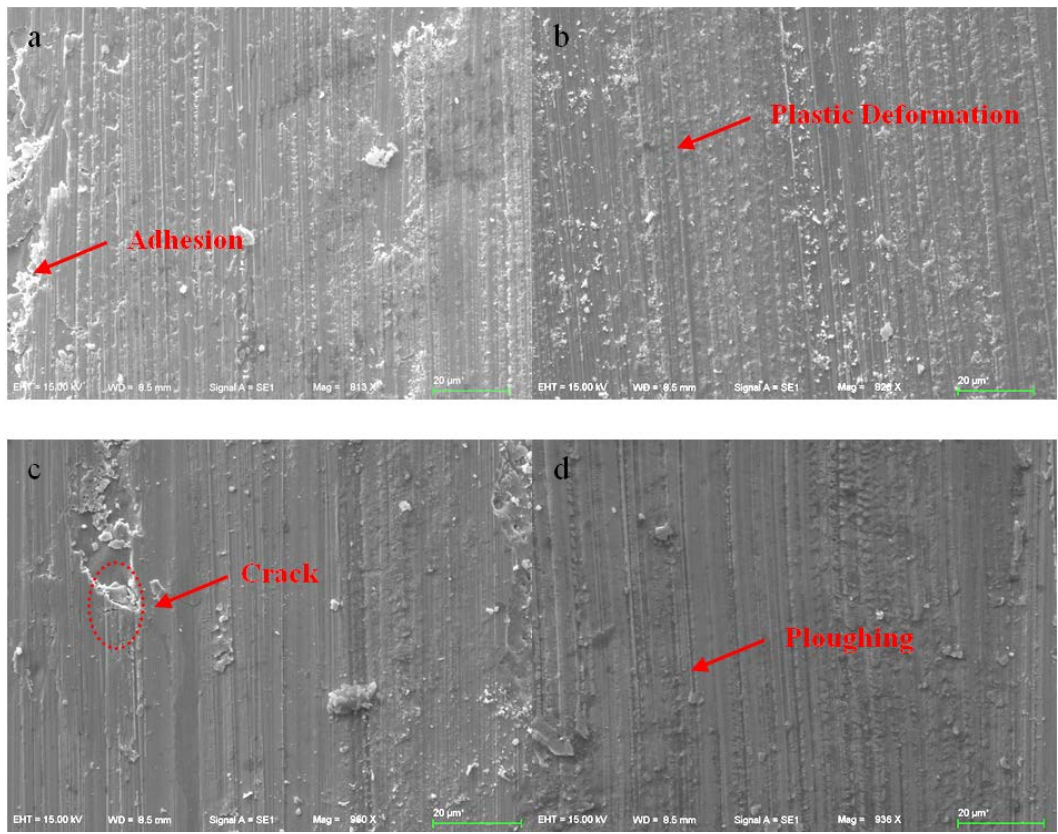

Fig. 5 High magnification SEM images of surface morphology of the wear tracks of graphene nickel composite coatings with different graphene content; (a) Ni, (b) $1 \%$ Gr, (c) $5 \%$ Gr and (d) 10\% Gr at a constant sliding speed of $25 \mathrm{~mm} / \mathrm{s}$ for $5 \mathrm{~min}$.
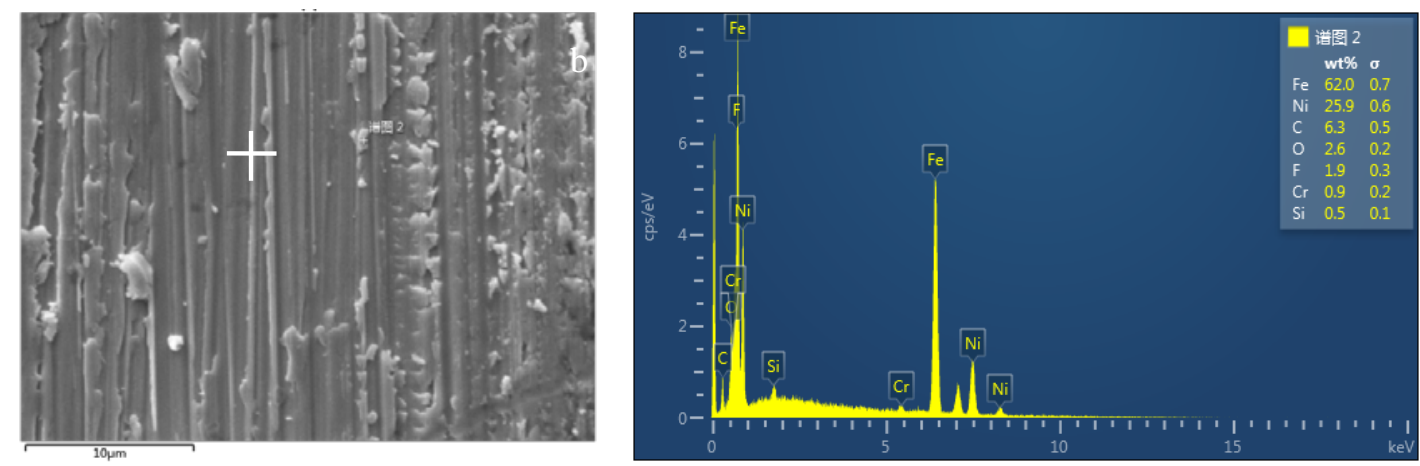

Fig.6 (a) SEM image of surface morphology of the wear tracks of laser sintered pure nickel coating, (b) EDS spectra of the marked point on (a).

Fig. 7 shows friction coefficient for graphene nickel composite coatings with varying graphene content at a constant sliding speed of $25 \mathrm{~mm} / \mathrm{s}$. As it can be seen clearly from Fig. 7, friction coefficient of the composite coatings were much lower than that of pure nickel coating. And it decreased with the graphene content increasing, which was due to graphene sheets prevented the direct contact between the nickel matrix and steel ball and the self-lubricating effect of graphene. It can be found from Fig. 7 that 5wt.\% graphene nickel coating has a higher frication coefficient than its neighbours. As shown in Fig. 8, there is relatively big high carbon content particles on the worn surface, this will make the carbon (come partly from graphene and partly from substrate) distributed uniformly in the matrix. And in Fig. 5c, crack can be found on the surface. These maybe result in a higher friction coefficient. 


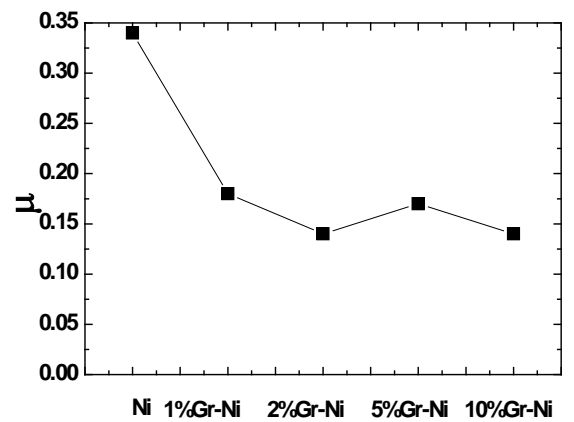

Fig. 7 Effect of the graphene content on friction coefficient of Gr-Ni composite coatings.
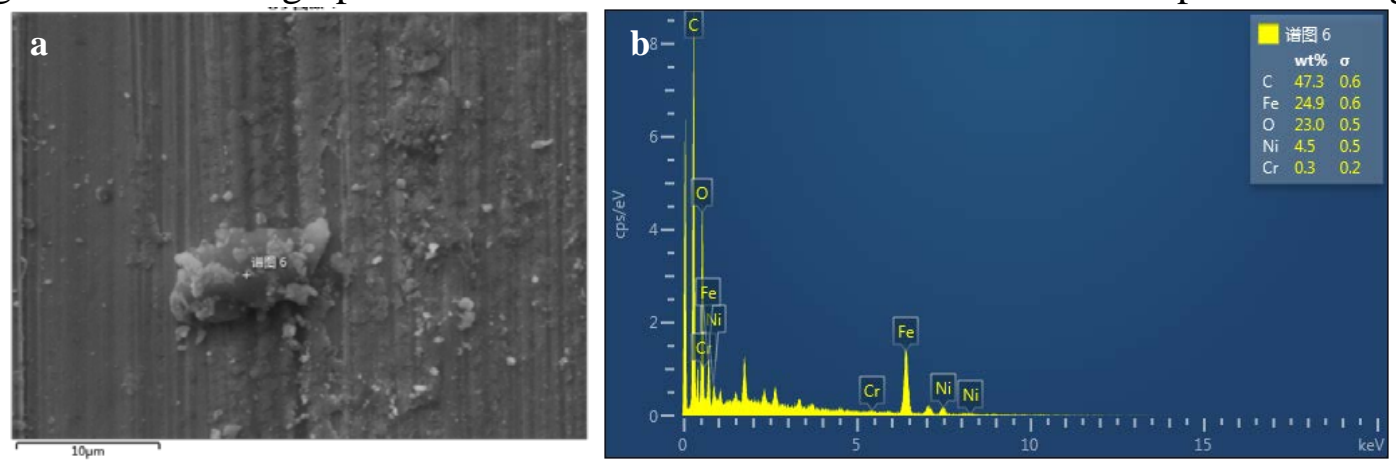

Fig. 8 (a) SEM image of surface morphology of the wear tracks of laser sintered 5\% Gr-Ni, (b) EDS spectra of the marked point on (a).

Fig. 9a is the worn surface image of $10 \mathrm{wt} . \% \mathrm{Gr}-\mathrm{Ni}$ nanocomposites. Fig. 9b-e are EDS maps of iron, oxygen, nickel and carbon in the worn surface. It can be seen form those elements EDS maps, that all the elements were distributed very homogeneously. It was not like the sectional EDS maps in our previous works[14], there, the distribution of those elements were not uniform. This is reasonable, because in the wear and frication experiments, the steel ball rubbed with the samples surface repeatedly. This will make the components of the surface mixed uniformly. Despite this, it still can be found from Fig. 9e, which is carbon EDS map, that carbon density was high at some small region, as marked in the yellow dotted line ellipse. This means graphene sheets were a little agglomerated there.

\section{Conclusion}

1wt. \%, 2wt. \%, 5wt. \% and 10wt. \% multilayer graphene composite coatings were prepared by laser sintering on AISI 4140 substrate plates. It was proved by Raman spectrum and SEM, TEM tests that graphene exist in the laser sintered graphene nickel composite coatings. With graphene sheets reinforcement, the composite coatings show a very high hardness value and improved modulus. The average hardness value is $12 \mathrm{GPA}$ and the average modulus value is193.04 GPa. The wear and friction experiment results showed the friction coefficients were greatly reduced with the increase of the graphene reinforcement. And the added graphene sheets can server as load bearing and solid lubrication components in the coating layer, this will improve the wear and friction properties of the composite coatings significantly. 

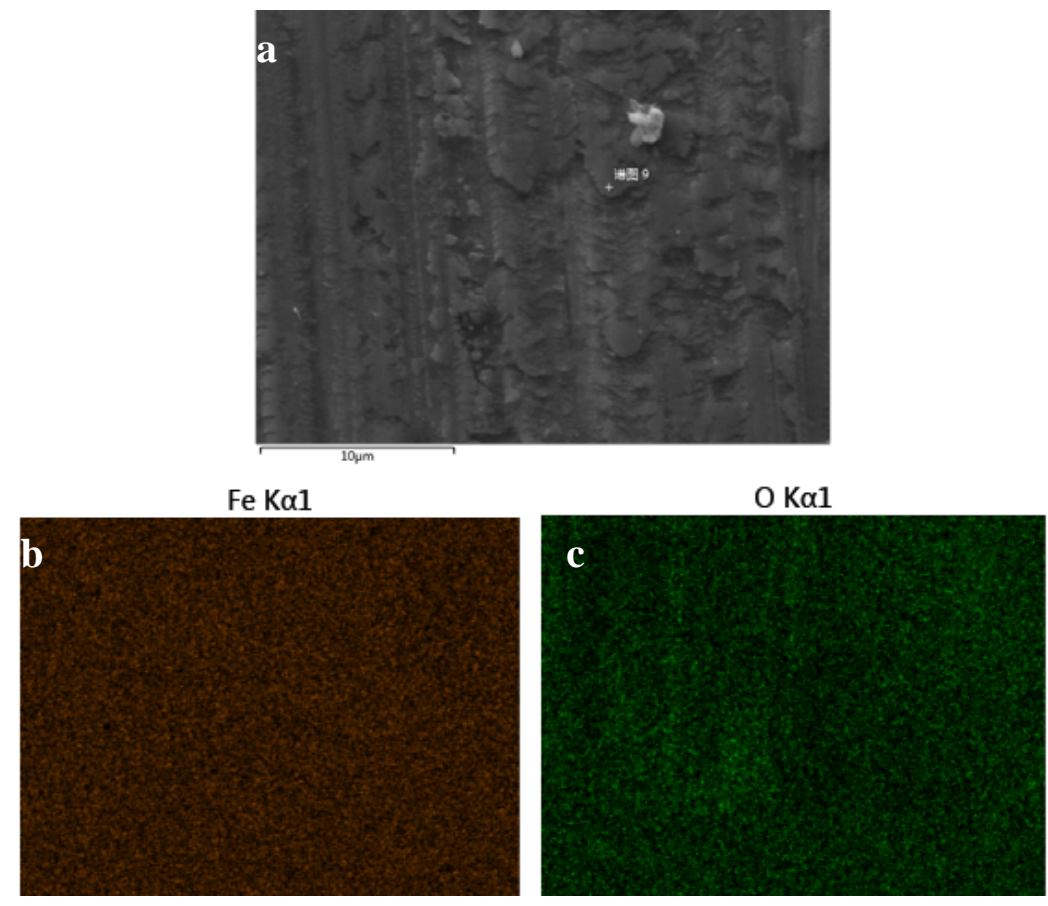

Ni Ka1

C Ka1_2
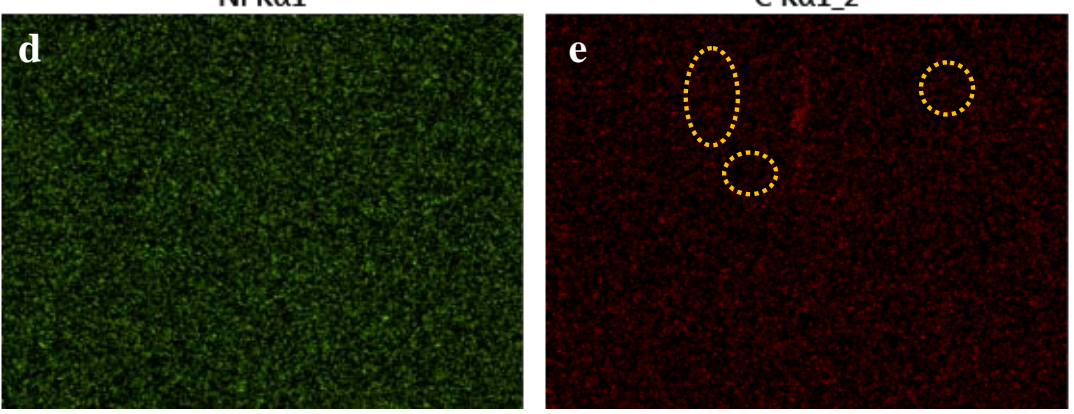

Fig. 9 (a) SEM image of worn surface of $10 \%$ Gr-Ni, (b), (c), (d) and (e) are Fe, O, Ni, C, EDS maps of (a).

\section{References}

[1] Farahmand, P., et al., Comparative study of the slurry erosion behavior of laser cladded Ni-WC coating modified by nanocrystalline WC and La2O3. The International Journal of Advanced Manufacturing Technology, 2015. 79(9): p. 1607-1621.

[2] Farahmand, P. and R. Kovacevic, Corrosion and wear behavior of laser cladded Ni-WC coatings. Surface and Coatings Technology, 2015. 276: p. 121-135.

[3] Szczygieł, B. and M. Kołodziej, Composite Ni/A12O3 coatings and their corrosion resistance. Electrochimica Acta, 2005. 50(20): p. 4188-4195.

[4] Hu, H.X., et al., Cavitation erosion and jet impingement erosion mechanism of cold sprayed $\mathrm{Ni}-\mathrm{Al} 2 \mathrm{O} 3$ coating. Nuclear Engineering and Design, 2011. 241(12): p. 4929-4937.

[5] Hongmin, K., Y. Zhaoyi, and Z. Ning, Preparation of Ni-SiC Composite Coating by Electrochemical Deposition. Rare Metal Materials and Engineering, 2015. 44(12): p. 2960-2964.

[6] Guo, B.-h., Z.-y. Wang, and H.-l. Li, Study on the Friction and Wear Behavior of a TA15 Alloy and Its Ni-SiC Composite Coating. Journal of Materials Engineering and Performance, 2016. 25(5): p. 1763-1772.

[7] Xia, F.-f., et al., Nanocomposite Ni-TiN coatings prepared by ultrasonic electrodeposition. Current Applied Physics, 2009. 9(1): p. 44-47. 
[8] Xia, F., et al., Preparation and corrosion behavior of electrodeposited Ni-TiN composite coatings. International Journal of Refractory Metals and Hard Materials, 2012. 35: p. 295-299.

[9] Tang, J.J., et al., The influence of size and distribution of graphite on the friction and wear behavior of Ni-graphite coatings. Surface and Coatings Technology, 2014. 252: p. 48-55.

[10] Yang, J., et al., Tribological behaviors of plasma sprayed CuAl/Ni-graphite composite coating. Tribology International, 2015. 90: p. 96-103.

[11] The preparation of carbon nanotube (CNT)/copper composites and the effect of the number of CNT walls on their hardness, friction and wear properties. Carbon, 2013.

[12] Alishahi, M., et al., The effect of carbon nanotubes on the corrosion and tribological behavior of electroless Ni-P-CNT composite coating. Applied Surface Science, 2012. 258(7): p. 2439-2446.

[13] Hu, Z., et al., Laser sintered single layer graphene oxide reinforced titanium matrix nanocomposites. Composites Part B: Engineering, 2016. 93: p. 352-359.

[14]Hu, Z., et al., Laser sintered graphene nickel nanocomposites. Journal of Materials Processing Technology, 2016. 231: p. 143-150.

[15]Algul, H., et al., The effect of graphene content and sliding speed on the wear mechanism of nickel-graphene nanocomposites. Applied Surface Science, 2015. 359: p. 340-348.

[16] Novoselov, K.S., et al., Electric Field Effect in Atomically Thin Carbon Films. Science, 2004. 306(5696): p. 666-669.

[17]Balandin, A.A., et al., Superior Thermal Conductivity of Single-Layer Graphene. Nano Letters, 2008. 8(3): p. 902-907.

[18]Lee, C., et al., Measurement of the elastic properties and intrinsic strength of monolayer graphene. Science, 2008. 321(5887): p. 385-8.

[19]Lee, C., et al., Elastic and frictional properties of graphene. physica status solidi (b), 2009. 246(11-12): p. 2562-2567.

[20]Kuang, D., et al., graphene nickle composite. Applied Surface Science, 2013. 273(0): p. 484-490.

[21]Ferrari, A.C., Raman spectroscopy of graphene and graphite: Disorder, electron-phonon coupling, doping and nonadiabatic effects. Solid State Communications, 2007. 143(1-2): p. 47-57.

[22]Ni, Z., et al., Raman spectroscopy and imaging of graphene. Nano Research, 2010. 1(4): p. 273-291.

[23]Casiraghi, C., et al., Raman Spectroscopy of Graphene Edges. Nano Letters, 2009. 9(4): p. 1433-1441.

[24]Dong, X., et al., Synthesis of graphene-carbon nanotube hybrid foam and its use as a novel three-dimensional electrode for electrochemical sensing. Journal of Materials Chemistry, 2012. 22(33): p. 17044-17048.

[25]Li, X. and B. Bhushan, A review of nanoindentation continuous stiffness measurement technique and its applications. Materials Characterization, 2002. 48(1): p. 11-36.

[26] Oliver, W.C. and G.M. Pharr, Measurement of hardness and elastic modulus by instrumented indentation: Advances in understanding and refinements to methodology. Journal of Materials Research, 2004. 19(01): p. 3-20.

[27] Wu, H., et al., Preparation of Ni-P-GO composite coatings and its mechanical properties. Surface and Coatings Technology, 2015. 272: p. 25-32. 